\title{
Primero cayó Pablo, después cayó Joaquín
}

Por Luis Fernando Rangel Flores

Universidad Autónoma de Chihuahua
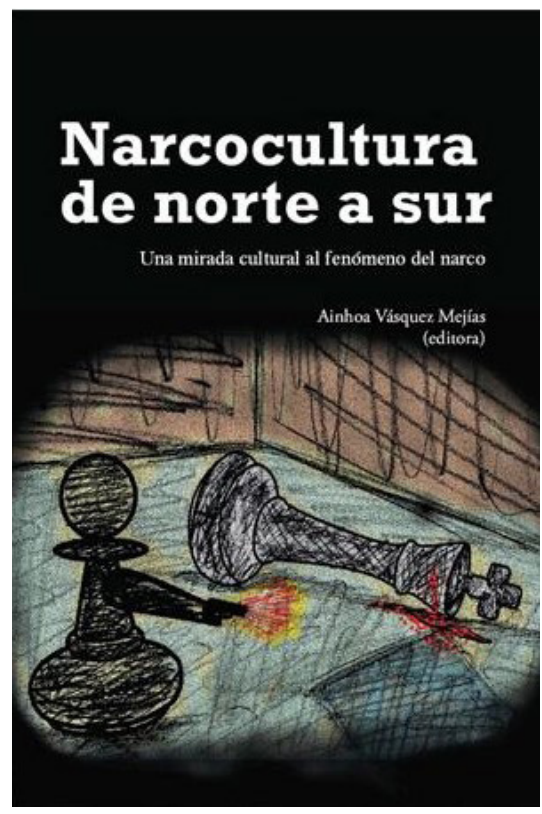

Ainhoa Vásquez Mejía (Ed). Narcocultura de norte a sur, notas sobre el narcotráfico en la cultura popular. México: UNAM, 2017. 223 págs.

\section{1.- El jefe de jefes, hablemos del todopoderoso.}

¿De qué hablamos cuándo hablamos del narco? La respuesta puede extenderse al infinito: desde la explosión mediática del fenómeno del tráfico de drogas en la década de los ochentas en Colombia y México, con la presencia del Cartel de Medellín, el Cartel de Guadalajara y el Cartel de Sinaloa, bajo la dirección de personajes como Pablo Escobar, Miguel Ángel Félix Gallardo y Joaquín "El Chapo" Guzmán, la palabra "narco" se volvió un prefijo que antecedió a todas las palabras que pudo. Comenzamos a hablar de narcocorridos, narcopolítica, narcoliteratura, narcoseries, narcoatentados, narcopelículas y hasta terminamos hablando de narcosatánicos, creando toda una estética del narcotráfico además de una cultura que giraba en torno al tráfico de drogas y el submundo en el que se ve inmerso. Así, las narrativas de la violencia que generó el narcotráfico, fueron ocupando lugares importantes dentro de la cultura popular y comenzaron a gestarse un sinfín de discursos que atravesaron todas las narrativas posibles. Sin duda la literatura, la música, el cine y la televisión fueron parte de este fenómeno como una de las representaciones más palpables. 
Por eso, si nos preguntamos cómo entender el narcotráfico, una de las posibles respuestas sería: desde la cultura popular y los productos de consumo que las masas generaron y adquirieron.

Narcocultura de norte a sur es un libro que nos plantea ante este mundo del hampa, del crimen, los lujos, las mujeres exuberantes, los hombres todopoderosos, los carros del año, los ríos de alcohol, la droga, los juniors, los cantantes de narcocorridos, los códigos de honor y el castigo, un mundo, pues, ocupado por el prefijo "narco". Narcocultura de norte a sur abre las interrogantes de una pregunta que difícilmente se puede responder, porque contrario a llevarnos de la mano por un sendero despejado, nos lleva al inicio del camino de una selva llena de árboles, animales peligrosos y caminos con encrucijadas a nuevos cuestionamientos. El conocimiento, pues, se queda en la reflexión de los distintos fenómenos en los que los autores nos muestran un panorama de donde se desprende un abanico de posibilidades. Ya queda en nuestras manos elegir.

Este libro, coordinado por Ainhoa Vásquez Mejías, reúne la labor de investigación de diez escritores que desde diferentes trincheras analizan cómo el narcotráfico ha permeado en diferentes expresiones de la cultura, con indagaciones que van desde la literatura, con novelas que se gestan con estructuras propias del discurso del corrido, esto es, narrar las hazañas de los hombres valientes en la legitimación del cantante/escritor, que desde la épica mira hacia el pueblo y se sirve de la voz coral, hasta las narcoseries que fundamentan el melodrama televisivo popularizado por las narrativas del amor y la tragedia. Encuentran en el camino las herramientas para analizar fenómenos tan diversos como la infancia, las estructuras patriarcales y capitalistas, o la historia que se atraviesa por la revolución y la guerrilla, además del reclamo en la voz del pueblo exigiéndole al gobierno lo que le corresponde, que finalmente el narcotráfico termina por cumplir en las regiones más inaccesibles del país, dando espacio a los narcoestados e indagando en las expresiones estéticas de la violencia y las nuevas posibilidades de la literatura en expresiones del lenguaje. ¿En qué momento la palabra "levantón" cambió de significado? ¿En qué momento una narcomanta se adentra el mundo de la microficción?

\section{2.- Lo siento sheriff, yo no sé cantar: la narcoliteratura ante la crítica y los discursos narrativos de la música, el cine y la tele- visión.}

Otra interrogante importante es plantearse ante la crítica y cuestio- 
narse por la Literatura Nacional, esa que se escribe desde el centro -en mayúsculas-y que forma canon. Y es que es sumamente conocida la disputa sostenida entre Rafael Lemus, con su famoso artículo titulado "Balas de salva" que apareció en la revista Letras Libres, y autores como Eduardo Antonio Parra o Elmer Mendoza. Varios autores de este libro abordan los cuestionamientos de Lemus y de Christopher Domínguez Michael respecto a la carencia de una estética definida, una estructura compleja y una obra cumbre de la llamada, de forma peyorativa, narcoliteratura. La respuesta a lo que Lemus y Domínguez Michael dicen, se responde de manera magistral con propuestas que se escriben desde las otras literaturas que no se encuentran en el centro y que, a fuerza de luchar, se han hecho de un lugar dentro del panorama literario.

Con obras como Contrabando de Víctor Hugo Rascón Banda o Trabajos del reino de Yuri Herrera, los autores refutan lo dicho por los críticos literarios. Encontramos en la primera la cumbre de la narconarrativa en una obra que casi se puede decir la inauguró: aquí la figura del escritor se sirve del testimonio, la autobiografía y otros géneros literarios para plasmar un fenómeno que desde los noventa ocurría, pero no a niveles tan mediáticos como lo fue con la guerra contra el narco emprendida por el gobierno de Felipe Calderón. La segunda, con un lenguaje sumamente cuidado, hace de la palabra su herramienta principal y mediante la figura del cantante de narcocorridos, nos introduce el mundo del narco. Estas dos obras se sirven, pues, de la figura del compositor y del narcocorrido para estructurarse.

Otras obras, nos dicen los autores, se construyen desde el pastiche. Desde diversos géneros que integran un corpus tan complejo como el narcotráfico. Explorando desde la novela policíaca, la novela negra, las técnicas cinematográficas o las bildungsroman, diversos autores no sólo de México y Colombia, sino de diferentes países como Chile, Estados Unidos, Argentina o España se han aproximado a este mundo. Y es que cabe destacar que el negocio del narcotráfico no sólo se encargó de llevar su mercancía a todo el mundo, sino de explotar mediáticamente en diferentes regiones. Así, con ejemplos de la Ciudad Letrada en obras de Juan Villoro, la novela de formación de Juan Pablo Villalobos con Fiesta en la madriguera o con novelas como las de Elmer Mendoza, que se sirven del detective, la narrativa se ha desbordado a un sinfín de posibilidades.

El mundo de la pantalla grande y la pantalla chica también nos ha mostrado grandes ejemplos de cómo funciona este mundo donde se desdibujan héroes y villanos. Los autores del libro abordan el cine y 
la televisión. En series latinoamericanas como Narcos, Narcos México, El Chapo o La reina del sur, películas como El Infierno, así como producciones norteamericanas famosas donde destaca Breaking Bad, se aborda el mundo desde los límites de lo bueno o lo malo, donde el bien no se enmarca dentro de lo establecido por la sociedad, sino en las acciones que benefician a los desamparados, y donde el mal se representa en la traición a la patria y las estructuras de gobierno. Aquellos que trafican se preocupan por los suyos. Aquellos que nos deben cuidar, no lo hacen.

Aquí, pues, ¿se trata de cantarle al narcotráfico o cantar contra el negocio ilegal? No cabe duda que los ídolos se alzaron en la figura del héroe: la sustitución del Estado por la figura del capo que se emparenta con Robin Hood es un hecho, pero también este canto es una crítica al sistema que se ha quebrantado.

\section{3.- Ya con esta me despido: Narcocultura de norte a sur, ¿buscan- do una nueva literatura latinoamericana?}

La narconovela llegó para implantarse como un referente de la narrativa latinoamericana e, inclusive, española: autores como Arturo Pérez Reverte han incursionado en la temática y desde aquí cabe preguntarse ¿se puede hablar de la narconovela como un género? Como los autores abordan a lo largo de Narcoliteratura de norte a sur, el discurso del narcotráfico ha desbordado todas las narrativas y ha encontrado lugar en un sinfín de expresiones y clasificaciones distintas. Aquí hablar de narcoliteratura puede entenderse más como un fenómeno mercantil o como una forma sencilla de clasificar algo tan complejo. El tema del narcotráfico lo vemos en novelas negras, novelas policiacas, novelas de formación (de-formación), novelas estructuradas como corridos, novelas testimoniales, biografías, autobiografías, crónicas, series televisivas, series en internet, películas, corridos (narcocorridos), rap (gangsta rap), poesía y una larga lista. Todos los autores nos plantean un recorrido por este mundo y estas interrogantes: la infancia que ve al narcotráfico, el cantante de narcocorridos que narra el mundo de la violencia, el escritor que regresa a su pueblo y se encuentra con el poder a manos de los narcotraficantes, el historiador que viaja a su pasado para encontrar las similitudes de la historia, ahora repetida en la barbarie. No nos encontramos ante un nuevo boom como lo fue el realismo mágico, nos encontramos ante un mundo violento que atravesó las narrativas de la literatura. ¿De nuevo nos observamos en el espejo de lo real maravilloso? Pensemos, pues, en que ya no hay una Remedios "La Bella" volando por los aires, sino una narcomanta clavada en el pecho de un cadáver y cabezas en las esquinas. 